\title{
Peranan MGMP Dalam Meningkatkan Kinerja Guru Mata Pelajaran Pendidikan Agama Islam SMA di Kota Balikpapan
}

\author{
Firman \\ Fakultas Keguruan dan Ilmu Pendidikan \\ Universitas Balikpapan \\ Email: firmanalfarabi72@yahoo.co.id
}

\begin{abstract}
Deliberation Subject Teacher (MGMPs) is a container for a meeting of subject teachers in the school. The organization was formed as a forum for the meeting of subject teachers, selaian, as a means silaturrahmi as well as organizations that accommodate a variety of ideas for teachers and also as a means of accommodating the various problems faced by the teachers in each school masing.ini prove so important in the formation MGMPs in addressing the problems faced by teachers in each educational unit. With over MGMPs teachers are expected to maintain the quality performance of duty as a teacher in accordance with the needs of society, especially in the working world. MGMPs participation in the process of improving the performance of teachers, are required to perform a variety of breakthroughs that will build a quality education. The purpose of this study is to explore some theories about MGMPs, and role in improving teacher performance PAI Balikpapan city high school, there is the implication to make the guidelines in the teaching process so as to produce teachers who have a good performance.
\end{abstract}

Keywords: MGMPs, and the performance of teach

\begin{abstract}
Abstrak
Musyawarah Guru Mata Pelajaran (MGMP) adalah wadah untuk pertemuan para guru mata pelajaran di sekolah. Organisasi tersebut dibentuk sebagai forum pertemuan para guru mata pelajaran, selaian itu juga sebagai sarana silaturrahmi serta sebagai organisasi yang menampung berbagai gagasan para guru dan juga sebagai sarana menampung berbagai permasalahan yang dihadapi guru di sekolah masing-masing.ini membuktikan bahwa begitu pentingnya pembentukan MGMP di dalam mengatasi persoalan yang dihadapi oleh guru di satuan pendidikan masing-masing. Dengan melalui MGMP diharapkan guru dapat mempertahankan kualitas kinerjanya dalam menjalankan tugas sebagai guru sesuai dengan kebutuhan masyarakat terutama dalam dunia kerja. Peran serta MGMP dalam proses peningkatan kinerja guru, dituntut untuk melakukan berbagai terobosan-terobosan yang akan membangun pendidikan berkualitas. Tujuan penelitian ini adalah untuk menggali beberapa teori tentang MGMP, dan perananya dalam meningkatkan kinerja guru PAI SMA kota Balikpapan, terkandung maksud menjadikan pedoman dalam proses mengajar sehingga mampu menghasilkan guru-guru yang memiliki kinerja baik.
\end{abstract}

Kata kunci : MGMP, dan kinerja Guru

\section{Pendahuluan}

Dalam UUD 1945 pada pasal 3 berbunyi pendidikan nasional berfungsi untuk mengembangkan kemapuan serta meningkatkan mutu kehidupan dan martabat manusia Indonesia dalam mewujudkan tujuan nasional. Sedangkan dalam pasal 4 berbunyi pendidikan Nasional bertujuan mencerdaskan kehidupan berbangsa dan mengembangkan manusia Indonesia seutuhnya yaitu manusia Indonesia yang beriman dan bertaqwa terhadap Tuhan Yang Maha Esa dan berbudi pekerti luhur, memiliki pengetahuan dan keterampilan, kesehatan jasmani dan rohani, kepribadian yang mantap dan mandiri serta rasa tanggung jawab kemasyarakatan dan kebangsaan. Dalam UUD 1945 nampak jelas bahwa pendidikan merupakan perhatian Negara 
cukup tinggi dalam hal ini upaya Indonesia .untuk menunjang hal tersebut diperlukan langkah-langkah strategis dan sinergis terutama terhadap guru karena Guru merupakan kondisi yang diposisikan sebagai garda terdepan dan posisi sentral di dalam pelaksanaan proses pembelajaran.

Oleh karena itu, di anatara langkah konkrit yang lakukan adalah pemberdayaan pelaksanaan kegiatan Musayawarah Guru Mata Pelajaran (MGMP. Musyawarah Guru Mata Pelajaran (MGMP) merupakan suatu wadah yang disediakan bagi para guru mata pelajaran sejenis untuk memecahkan berbagai persoalan yang dihadapi dalam upaya peningkatan kinerja guru , dengan demikian peningkatan MGMP merupakan masalah yang sangat mendesak untuk menjadi perhatian dalam rangka menciptakan guru yang professional dan memiliki kinerja yang berkualitas.

Dengan melalui organisasi MGMP diharapkan guru dapat mempertahankan kualitas kinerjanya dalam menjalankan tugas sebagai guru sesuai dengan kebutuhan masyarakat terutama dalam dunia kerja. Peran serta MGMP dalam proses peningkatan kinerja, maka dituntut untuk senantiasa melakukan berbagai terobosan-terobosan yang pada nantinya akan membangun pendidikan yang berkualitas. Pendidikan yang berkualitas akan memiliki nilai jual yang tinggi. Sehingga dengan penyelenggaraan MGMP memiliki peran yang sangat strategis dalam upaya peningkatan kinerja guru.

Agar kegiatan MGMP bermanfaat dan dapat berjalan sesuai dengan yang diharapkan, hendaknya para anggota dilibatkan pada setiap tahapan kegiatan organisasi seperti tahap perencanaan program, pelaksanaan, dan tahap evaluasi. Namun hasil penelitian menunjukkan bahwa para guru pada peningkatan kualitas pendidikan di dasarnya hanya dilibatkan dan terlibat secara optimal pada tahap pelaksanaan aktivitas MGMP saja. Guru tidak banyak dilibatkan pada tahap perencanaan seperti dalam penyusunan program maupun penetapan jadwal. Terlihat bahwa peranan pengurus lebih dominan dan penyusunan program ini juga tidak dilakukan melalui analisis kebutuhan guru. Begitu juga halnya pada tahap evaluasi, di mana guru hanya sebagai objek evaluasi, yaitu orang yang dievaluasi.

Kaitannya dengan hal tersebut di atas, Musyawarah Guru Mata Pelajaran Pendidikan Agama Islam tingkat SMA kota Balikpapan sebagai organisasi guru mata pelajaran memiliki peran yang sangat strategis untuk meningkatkan kinerja guru pendidikan Agama di kota Balikpapan. Oleh karena itu penting dan sangat menarik untuk dikaji dan diteliti berkaitan dengan bagaimana keberadaan Musyawarah Guru Mata Pelajaran (MGMP) pendidikan Agama Islam dalam mendorong meningkatkan kinerja guru.

\section{Metode Penelitian}

Dalam penelitian ini, Penelitimenggunakan pendekatan kualitatif, yaitu melihat, mengkaji dan menganalisis teori-teori yang berkaitan dengan MGMP, dan kinerja guru. Yaitu dengan mengkaji tentang teori dan melakukan pengamatan organisasi MGMP beserta kinerja guru itu sendiri. Dari kajian tersebut dapat dijelaskan proses pengumpulan data atau reduksi data yaitu dengan cara membuat rangkuman tentang peranan MGMP dan kinerja guru, serta aspek-aspek permasalahan yang terjadi pada organisasi MGMP tersebut. Sehingga memudahkan peneliti melakukan analisis berikutnya. Selanjutnya dilakukan reduksi data, maka perlu dilakukan 
didisplay data. Dengan display data akan membantu bagi peneliti sebagai media penjelas obyek yang diteliti yaitu tentang peranan MGMP PAI SMA se kota Balikpapan dalam meningkatan kinerja guru. selain itu, proses reduksi data ditujukan untuk menyaring, memilih dan memilah data yang diperlukan untuk menyusunnya ke dalam suatu urutan rasional dan logis,serta mengaitkannya dengan aspek-aspek yang diteliti. Selanjtnya adalah melakukan atau pengambilan kesimpulan dan verivikasi data tentang obyek yang diteliti.

\section{Hasil Penelitian}

Tujuan pendidikan Nasional seperti yang tertuang dalam UU Nomor 20 tahun 2003 merupakan sebuah amanat yang ketercapaiannya harus diupayakan secara optimal. Dalam undang-undang tersebut secara eksplisit disebutkan bahwa pendidikan bertujuan untuk berkembangnya potensi peserta didik agar menjadi manusia yang beriman dan bertaqwa terhadap Tuhan Yang Maha Esa, berakhlaq mulia, kreatif, mandiri, dan menjadi warga Negara yang demokratis dan bertanggung jawab.

Pendidikan agama Islam pada sekolah memiliki peranan yang sagat strategis dalam system pendidikan Nasional, terutama dalam rangka membangun karakter bangsa yang beriman, bertakwa dan berakhlak mulia dan mampu menjaga kedamaian dan kerukunan hubungan inter dan antar umat beragama. dalam hal tersebut fungsi PAI ini sangat selaras dengan fungsi pendidikan Nasional yaitu mengembangkan kemampuan dan membentuk watak serta peradaban bangsa yang bermartabat dalam rangka mencerdaskan kehdupan bangsa, yang bertujuan berkmbangnya potensi peserta didik agar menjadi manusia yang beriman dan bertaqwa kepada Tuhan Yang Maha Esa, berakhlak mulia, sehat, berilmu, cakap, kreatif, amndiri, dan menjadi warga Negara yang demokratis serta bertanggung jawab.

Untuk menjawab tantangan tersebut, Musaywarah Guru Mata Pelajaran (MGMP) Pendidikan Agama Islam merupakan wadah bagi para guru pendidikan Agama Islam Sekolah Menengah Atas (SMA) untuk mengadakan diskusi, meningkatkan tali silaturrahmi, meningkatkan kompetensi guru, baik Paedagogik, Sosial, Kepribadian dan professional antar guru pendidikan Agama Islam SMA se Kota Balikpapan, sehingga mampu melahirkan pesrta didik sebagaimana yang telah disebutkan dalam Undang-undang maupun dalam system pendidikan Nasional.

MGMP PAI SMA se Kota Balikpapan lahir untuk merespon tantangan dari perkembangan Ilmu Pengetahuan dan Teknologi, sehingga guru mata pelajaran PAI yang memiliki varian dari segi tingkat kemampuan akademiknya serta latar belakang pendidikan yang berbeda bahkan social kepribadian yang berbeda perlu sarana komunikasi dan peningkatan kompetensi yang meliputi :

a. Pendalaman materi

b. Penguasaan sumber/media belajar

c. Penguasaan teknik, metode, model pembelejaran serta teknik evaluasinya

d. Penguasaan terhadap Adminstrasi khususnya adminstrasi pendidikan

e. Penanaman nilai-nilai karakter

\section{Program Kerja MGMP}

Untuk mencapai tujuan organisasi, MGMP PAI SMA Kota Balikpapan telah menetapkan program kerja sebagai tanggung jawab yang harus dilaksanakan selama periode kepengurusan tersebut. Program kerja tersebut merupakan langkah yang lakukan dalam rangka untuk meningkatkan profesionalisme guru PAI sehingga pada akhirnya melahirkan guru yang memilki kinerja baik. 
Jenis program kerja MGMP PAI SMA Kota Balikpapan adalah :

1. Mengadakan pertemuan Rutin

a. Pertemuan 2 minggu sekali guruguru di sekolah masing-masing

b. Pertemuan bulanan untuk anggota MGMP Pertemuan tersebut dilaksanakan sekali dalam sebulan.

c. Pertemuan semesteran

Dalam pertemuan setiap semester agenda yang menjadi pembahasan selain perkembangan pendidikan yang terpenting adalah menyusun Silabus, RPP, Bahan Ajar serta perangkat pembelajaran,

2. Kegiatan Insidental

Kegiatan insidental maksudnya kgiatan yang dilakukan secara insiden, dalam arti pertemuan tersebut tidak dilaksanakan secara rutin, akan tetapi dilaksanakan dalam waktu-waktu tertentu apabila ada agenda mendadak atau sifatnya mendesak. Kegiatan ini sering dilaksanakan walaupun tidak menentu pelaksanaannya, mengikuti perkembangan baik di institusi kementerian pendidikan maupun kementerian agama .

\section{Kegiatan Khusus}

Kegiatan khusus adalah kegiatan yang dilaksanakan secara khusus yang diagendakan oleh pengurus karena dianggap sebagai sesuatu yang mutlak harus dilaksanakan oleh MGMP dalam meningkatkan wawasan dan kompetensi serta kinerja guru. Peningkatan kompetensi yang dimaksud bukan hanya berkaitan akademeik akan tetapi juga non akademik terkandung maksud untuk membekali guru bukan hanya secara akademisnya tetapi juga kemapuan social maupun kepribadian guru. Kemampuan seorang guru PAI bukan hanya dihadapan murid tetapi juga ketika berada di lingkungan masyarakat.

\section{Peranan MGMP}

Sebagai wadah dalam peningkatan profesionalisme guru, Musyawarah Guru
Mata Pelajaran (MGMP) sangat berperan dalam peningkatan profesionalisme. Oleh karena itu MGMP mempunyai peran yang sangat penting dalam upaya peningkatan kinerja Guru. Peranan MGMP adalah :

1. Melaksanakan pengembangan wawasan, pengetahuan dan kompetensi, sehingga memilki dedikasi yang tinggi.

2. Melakukan refleksi diri ke arah pembentukan profil guru yang yang professional.

MGMP PAI SMA Kota Balikpapan memiliki peran yang sangat penting bagi anggotanya .Adapun peranan MGMP bagi guru PAI adalah :

a. Sebagai Kebutuhan dalam peningkatan karir bagi seorang guru

b. Sebagai guru PNS dalam kenaikan pangkat/golongan ada SKP yang di dalamnya terdapat penilaian kinerja Guru (PKG) juga dalam SKP terdapat penilaian berkelanjutan yang mana di dalamnya terdapat MGMP.dapat meningkatkan kompetensi guru.

c. Sebagai sarana dalam peningkatan kompetensi guru

d. Sebagai sarana sharing pengetahuan, pengalaman ataupun informasi.

\section{Tujuan MGMP}

Sebagai organisasi profesi, MGMP mempunyai beberapa tujuan. MGMP PAI kota Balikpapan telah merumuskan beberapa tujuan yaitu :

1. Membina kerja sama antar pengajar mata pelajaran PAI

2. Menumbuhkan kegairahan bagi dalam meningkatkan kemampuan dan keterampilan dalam mempersiapkan, melaksankan dan mengevaluasi program .

3. Meningkatkan kemampuan dan kemahiran guru dalam proses belajar, sehingga dapat menunjang usaha pemerataan dan peningkatan mutu pendidikan . 
4. Saling tukar informasi dan pengalaman dalam rangka mengikuti perkembangan Ilmu Pengetahuan dan Teknologi (IPTEK) serta pengembangan metode teknik mengajar.

5. Meningkatkan mutu keterampilan dan profesi guru PAI dan tujuan pendidikan nasional dapat tercapai.

\section{Manfaat MGMP}

Ada beberapa manfaat yang dapat kita lihat dari MGMP seperti :

1. Menjadi bahan kajian untuk pngembangan keilmuan mata pelajaran Pendidikan Agama Islam

2. Menyusuan program pembelajaran termasuk penyusunan silabus, program Tahuan, program semester, penilaian, kisi-kisi soal, pembuatan soal bahkan analisis soal.

3. Mengembangkan pembelajaran yang berbasis TIK

4. Menjadi masukan bagi pengembangan penelitian sebagai penunjang profesionalisme guru.

Untuk MGMP PAI SMA se Kota Balikpapan mempunyai beberapa manfaat bagi anggotanya.manfaat MGMP PAI SMA adalah :

a. Menciptakan ukhuwah Islamiah (persaudaraan) sesama guru pendidikan Agama Islam.

b. Guru pendidikan Agama Islam SMA memiliki semangat yang tinggi dalam meningkatkan keterampilan, mempersiapkan, melaksanakan, mengevaluasi pembelajaran di sekolah masing-masing dengan indicator nilai ujian siswa.

c. Setiap guru pendidikan agama Islam akan memiliki sejumlah perangkat pembelajaran yang sesuai dengan kondisi sekolah masing-masing sehingga pelaksanaan pembelajaran berjalan dengan baik.

Memberikan kemudahan bagi siswa-siswi dalam memahami materi pembelajaran semakin baik

\section{Kinerja Guru}

Kinerja guru adalah kemampuan dan usaha guru untuk melaksanakan tugas pembelajaran sebaik-baiknya dalam perencanaan program pengajaran, pelaksanaan kegiatan pembelajaran dan evaluasi hasil pembelajaran. Kinerja guru yang dicapai harus berdasarkan standar kemampuan profesional selama melaksanakan kewajiban sebagai guru di sekolah.

\section{Indikator Kinerja Guru}

Indikator penilaian kinerja guru dalam hal ini adalah ada tiga aspek yaitu

1. Rencana pemebelajaran atau yang lebih dikenal dengan Rencana Pelaksanaan Pembelajaran (RPP)

2. Prosedur Pelaksanaan (classroom procedure) dan hubungan antar pribadi (interpersonal pribadi)

3. dan penilaian pembelajaran.

\section{Faktor-Faktor Kinerja Guru}

Faktor yang mempengaruhi kinerja guru dalam melaksanakan tugas sebagai guru adalah

pertama : pendidikan guru, kualifikasi pendidikan guru sangat mempengaruhi tindakan kinerja guru, dengan pendidikan yang dimilikinya, seorang guru melaksanakan tugas sebagai kapsitas guru atau pendidik, menjadi professional di bidangnya masing-masing sesuai dengan tingkatan pendidikannya.

kedauasupervisi pengajaran kegiatan supervise dilaksanakan untuk mengetahui tingkat kemampuan seorang guru dalam menggunakan berbagai metode, bahan ajar, perangkat pembelajaran. Kepala sekolah melakukan pembinaan, bimbingan. Pengawasan, dan bantuan maslaha yang dihadapi oleh guru yang bersangkutan.

ketiga. Program penataran, kegiatan penataran yang diikuti oleh guru adalah 
sebagai sarana untuk menambah dan mengembangkan wawasan dibidang akademiknya serta melatih bagaimana keterampilan dalam mengajar.

Dalam penelitian ini mengkaji tentang peranan MGMP dalam meningkatkan kinerja guru PAI SMA kota Balikpapan. Seperti telah disebutkan sebelumnya bahwa MGMP memiliki manfaat, tujuan serta peranan dalam pengembangan profesionalisme guru. Profesionalaisme guru tidak bisa terlepas dari kinerja guru, Guru yang professional akan memiliki kinerja yang lebih baik. Sebagai guru yang berkinerja baik, guru PAI SMA Balikpapan pada umumnya telah memiliki kinerja yang lebih baik. Hal tersebut dapat dibuktikan dengan produk dari hasil MGMP berupa perangkat pembelajaran seperti silabus, RPP, prota, prosem, analisis soal, kisikisi soal serta pembuatan bahan ajar bahkan kegiatan work shop sering dilaksanakan oleh guru-guru PAI SMA.

\subsubsection{Kontribusi MGMP PAI dalam} pencapaian Tujuan Pendidikan Nasional

Untuk mencapai tujuan yang dimaksud, guru sebagai pelaksana memerlukan penegetahuan, keterampilan serta langkah-langkah konkrit terhadap peserta didik. Oleh karena itu dibutuhkan program kerja yang matang dalam MGMP. Untuk Program kerja yang telah dirancang Musaywarah Guru mata pelajaran (MGMP) Pendidikan Agama Islam SMA seBalikpapan telah memberikan konstribusi bagi pengembangan dunia pendidikan khususnya di kota Balikpapan, ada beberapa program yang telah dilaksanakan seperti :

1. Pengembagan perangkat KBM mulai dari analisis KI-KD

2. Penyusunan Kisi-kisi soal setiap semester

3. Penyusunan RPP

4. Penyusunan format penilaian

5. Penyusunan bahan Tayang pembelajaran untuk semua tingkatan
6. Penyusunan alat evaluasi

7. Pembahasan soal USBN

8. Pembuatan bahan ajar

9. Penembangan model-model pembelajaran

\section{Kesimpulan}

Musyawarah Guru Mata Pelajaran( MGMP) pada hakikatnya sebagai sarana/ untuk berkumpulnya guru mata pelajaran yang sejenis untuk membahas persoalanpersoalan yang berkaitan tentang mata pelajaran yang bersangkutan, termasuk di dalamnya adalah tentang pembuatan perangkat pembelajaran, pembuatan bahan ajar, metode maupun-masing. model pembelajaran berdasarkan lingkungan sekolah masing, selain itu, tentu untuk saling embagi informasi pendidikan yang bersifat kekinian.

Kinerja guru adalah kemampuan dan usaha guru untuk melaksanakan tugas pembelajaran sebaik-baiknya dalam perencanaan program pengajaran, pelaksanaan kegiatan pembelajaran dan evaluasi hasil pembelajaran. Kinerja guru yang dicapai harus berdasarkan standar kemampuan profesional selama melaksanakan kewajiban sebagai guru di sekolah. Berkaitan dengan kinerja guru dalam melaksanakan kegiatan belajar mengajar, terdapat Tugas Keprofesionalan Guru menurut UndangUndang Republik Indonesia Nomor 14 Tahun 2005

\section{Daftar Pustaka}

Anwar, Prabu Mangkunegara, 2005, Evaluasi Kinerja SDM, Bandung Rafika Aditama.

Gomes, Faustino Cardoso, 2003, Manajemen Sumber Daya Manusia, Yogyakarta Andi Offset.

Fattah Nanang, 1999. Landasan Manajemen, Bandung Rosda Karya 
Pengajaran dan Pembelajaran, Yogyakarta Pustaka belajar

Rusman 2014, Model-model

Pembelajaran, Jakarta Raja Grafindo

Persada

Tilaar H. A. R. 2001 .Beberapa Agenda Reformasi Pendidikan Nasional Dalam perspektif abad 21 . Magelang: Indonesia Tera .

Rahman, Muhammad, 2014, Kode Etik

Profesi Guru, Jakarta Prestasi Pustaka.
Sadili Samsuddin 2005, Manajemen Sumber Daya Manusia Bandung Pustaka Setia

Sedarmayanti 2001, Sumber Daya Manusia Dan Produktifitas Kerja, Bandung Mandar Maju

Simamora Hendry 2004, Manajmen Sumber Daya Manusia, Yogyakarta YKPN 